\title{
SENTIDOS SEDUCIDOS. ASPECTOS NEUROCOGNITIVOS DE LA LECTURA POÉTICA (SOBRE UN POEMA DE VERLAINE) ${ }^{1}$
}

\author{
SEDUCED SENSES. NEUROCOGNITIVE ASPECTS \\ OF POETRY READING (SOBRE UN POEMA DE VERLAINE)
}

\author{
Amelia GAMONEDA LANZA \\ Universidad de Salamanca \\ gamoneda@usal.es
}

Resumen: Las desviaciones de sentido que fundan el lenguaje poético son aquí objeto de una aproximación neurocognitiva a través de las vías de lectura (fonológica y léxica) que vinculan las áreas cerebrales implicadas en el proceso: la del reconocimiento visual de las letras, la de atribución de sonido y la de atribución de sentido. Para ello se rentabilizan conceptos tales como «bigrama», «arborescencia de la palabra» o amorçage. Sobre un poema de Verlaine, se estudian casos de homofonía, rébus y atracción semántica en los que los sentidos seducidos son tanto físicos como léxicos.

1 Este artículo ha sido realizado en el seno del Proyecto de Investigación Inscripciones literarias de la ciencia: ámbitos interdiscursivos, transferencias conceptuales y procesos semióticos (ILICIA). Junta de Castilla y León, Ref. SA021A11-1, Universidad de Salamanca. 
Abstract: Deviations of sense of poetic language are studied here in a neurocognitive approach through modes of reading (phonological and lexical) concerning the brain areas involved in the process: the visual recognition of letters, the allocation of sound and the meaning attribution. For this purpose, concepts such as «bigram», «tree structure of the word» or amorçage are analyzed. About a poem by Verlaine, we study some cases of homophony, rebus, and semantic attraction in which the senses are seduced both physical and lexicaly.

Palabras clave: Neurocognición. Lectura. Error poético. Bigramas. Rébus. Verlaine.

Key words: Neurocognition. Reading. Error poetic. Bigrams. Rebus. Verlaine.

El acto de escribir exige siempre un «cierto sacrificio del intelecto». Bien sabemos, por ejemplo, que las condiciones de la lectura son incompatibles con una precisión excesiva del lenguaje (Valéry, 1991: 12).

\section{ERROR DE LECTURA Y SENTIDO SEDUCIDO}

Paul Valéry quizá encontraría abusivo que sus palabras encabecen estas líneas, pues más que de una falta de precisión del lenguaje, se tratará aquí de un franco error de lectura. Eso sí, de un error que se pretende vinculado a una cualidad poética. El caso concierne a la última palabra de un conocido soneto del simbolista Verlaine, titulado «Mon rêve familier»:

Je fais souvent ce rêve étrange et pénétrant D'une femme inconnue, et que j'aime, et qui m'aime,

Et qui n'est, chaque fois, ni tout à fait la même

Ni tout à fait une autre, et m'aime et me comprend.

Car elle me comprend, et mon coeur transparent

Pour elle seule, hélas! cesse d'être un problème

Pour elle seule, et les moiteurs de mon front blême,

Elle seule les sait rafraîchir, en pleurant.

Est-elle brune, blonde ou rousse? Je l'ignore.

Son nom? Je me souviens qu'il est doux et sonore,

Comme ceux des aimés que la Vie exila. 
Son regard est pareil au regard des statues, Et, pour sa voix, lointaine, et calme, et grave, elle a L'inflexion des voix chères qui se sont tues (Verlaine, 1958) ${ }^{2}$.

En numerosas ocasiones — dentro del ámbito de mi docencia de Literatura Francesa-, he podido comprobar que la comprensión de este poema por parte de los lectores no francófonos atribuía a la forma verbal última «se sont tues» el significado de «se han matado», corregido enseguida por un «se han muerto» que ahondaba en el error, y, solo después de mediar la reflexión, desechado en favor de su recto sentido: «se han callado» ${ }^{3}$. La forma «tues» [ty], obviamente, es el participio del verbo «taire», en femenino, cuyo significado es «callar». A tal forma, los alumnos estaban atribuyendo el significado de «se sont tuées» [tye], esta sí, participio del verbo «tuer» («matar»). Este —en principio- burdo error se repetía tan sistemáticamente que empezó a abrirse paso la sospecha de que no fuera tan burdo e injustificado. Además, el error de los lectores no francófonos se veía acompañado por ciertas vacilaciones momentáneas de los lectores francófonos. Mi hipótesis hoy es que la equivocación tenía causas residentes en el propio poema, más que en la ignorancia del alumnado. Y que estas causas poemáticas convierten el error en el resultado de una seducción de sentido, esto es, en el resultado de una modificación de lenguaje $e^{4}$ que rompe la univocidad significante del signo «se sont tues». Es más, el significado erróneo generado por vía de seducción («se han matado») — es decir, el que la voz evocada

\footnotetext{
2 «Mi sueño habitual: A menudo tengo este sueño extraño y penetrante: / el de una mujer desconocida a la que amo y que me ama, / y que de una vez a otra no es del todo la misma / ni es otra del todo, y me ama y comprende. //Y es que sí me comprende, y, solo transparente / para ella, mi corazón deja de ser un problema / para ella sola, y el sudor de mi pálida frente / solo ella lo sabe refrescar, con su llanto. // ¿Es morena, pelirroja o rubia? No sé. / ¿Su nombre? Lo recuerdo como suave y sonoro / como aquéllos, amados, que la vida exilió. // Su mirada asemeja la mirada de estatua, / y, en cuanto a su voz, lejana, tranquila, grave, tiene / la inflexión de las voces queridas y ya calladas» (La traducción es mía).

${ }^{3}$ Un somero recorrido por las traducciones que del poema ofrece Internet permite recolectar, junto al correcto «que se han callado», los ya conocidos «que se han matado», o «que se fueron». Entre las traducciones publicadas en papel se registra también esta variedad: por ejemplo, la de Manuel Machado en la editorial Renacimiento (2007) dice: «que se han callado». La traducción de Ramón Hervás en Ediciones 29 (1975) reza, sin embargo, «que se han matado».

${ }^{4}$ Como afirma Baudrillard, «la séduction représente la maîtrise de l'univers symbolique, alors que le pouvoir ne représente que la maîtrise de l'univers réel» (Baudrillard, 1980: 19). La seducción es pues la imposición de un lenguaje. Un sentido seducido o erróneo como el que abordo aquí se encontraría concernido por un tipo de funcionamiento de los signos descrito en estos términos: «Peut-on imaginer une théorie qui traiterait des signes dans leur attraction séductrice, et non dans leur contraste et leur opposition? Qui briserait définitivement la spécularité du signe et l'hypothèque du référent? Et où tout se jouerait entre les termes dans un duel énigmatique et une révérsibilité inexorable?» (Baudrillard, 1980: 143).
} 
en el poema posea la inflexión de las voces queridas que han muerto- no es completamente arbitrario, pues se halla engranado en un régimen de sentido sostenido a lo largo de todo el texto. Antes de proceder a la aproximación cognitiva de la lectura de este final del poema — aproximación que abordará las posibles causas de la seducción de sentido que afecta a su última forma verbal- parece pertinente proporcionar un marco comprensivo del mencionado régimen de sentido a través de un breve análisis poético.

Ciertamente, la clave homofónica sobre la que suena la conocida musicalidad verlainiana en este poema es perceptible a primera escucha: la repetición de «aime» [cm] (del verbo «amar») se oye hasta ocho veces en el poema, contando las incluidas en «même» (mismo), «problème»y «blême», y la variante fónica (con «e» cerrada) «et me comprend» (en el verso cuarto). Del mismo modo, la homofonía repetida entre «m'aime» («me ama») y «même» («mismo») pone sobre la pista de un sueño en el que la mujer desconocida y amante es una segregación del propio soñador, de «soi même» (de «sí mismo»). La confusión entre sujeto y objeto de amor se despliega en el poema en composiciones de imágenes que expresan una relación de inclusión que es al tiempo comprensión transparente entre los amantes («Car elle me comprend, et mon coeur transparent / Pour elle seule, hélas! cesse d'être un problème»), o en coincidencias de carácter especular en las que las humedades de un rostro reflejan el llanto del otro. Sin embargo, la ignorancia sobre la identidad de la mujer se certifica en los dos tercetos, que confiesan el desconocimiento de su nombre y su única pervivencia en la memoria como rastro de sonido «suave y sonoro». Y en el que pudiera ser - al final del poema- desvanecimiento del sueño en la vigilia, solo parece quedarle al poeta el sonido de la voz de ella: nuevamente una reminiscencia sonora. Dos sonidos, el del nombre y el de la voz, que tal vez puedan resumirse en uno: quizá esa voz grave y tranquila ha pronunciado durante el sueño su propio nombre, el nombre ahora olvidado. Y esta confluencia también tendrá cierta importancia al final de estas páginas.

La explicación evidente del error en torno a «se sont tues» reposa sobre la semejanza gráfica y fónica de su participio con el del verbo «tuer» y sobre el contexto que proporciona el poema: este acerca explícitamente el sonido del nombre de la mujer al de los nombres de aquellos seres ya exiliados de la vida; habla de su mirada comparándola a la de las estatuas, cuyos ojos vacíos certifican su falta de vida; y encuentra semejanza entre el sonido de la voz de la mujer con el de otras voces amadas que se han callado (y se entiende que definitivamente). Es obvio que «callarse» es aquí una metonimia de «morirse». El efecto poético del error de lectura no es pues especta- 
cular, y uno se explica intuitivamente la atracción de sentido que se produce entre «se sont tues» y «se sont tuées». Pero el problema no es la comprensión de la metonimia, sino la franca sustitución de un significado por otro, lo que podría considerarse culminación del proceso metonímico $-\mathrm{y}$ su destrucción, por cierto- .

Tal eficaz operación de seducción del sentido sucede a espaldas de todo proceso consciente, y, de este modo, «sacrifica mucho intelecto», que diría Valéry. Pero ello no quiere decir que escape al funcionamiento de los procesos cognitivos de la lectura. Un análisis detallado de éstos podría refrendar que la imperfección lectora está implicada en los fenómenos poéticos ${ }^{5}$.

\section{LAS DOS VÍAS DE LECTURA}

Según Stanislas Dehaene (2007) — psicólogo neurocognitivo experimental y experto en el campo de la lectura- coexisten en nuestro cerebro dos vías de lectura que todos utilizamos: la del sentido (léxica) y la de los sonidos (fonológica). Ambas se activan simultáneamente y normalmente colaboran - pues una sola de ellas no puede leer todas las palabras de una lengua-, pero también se enfrentan y pueden tener sus disensos. La vía léxica atribuye directamente sentido desde las áreas de reconocimiento visual a las palabras conocidas, y, entre ellas, especialmente a las de pronunciación irregular — como, por ejemplo, «monsieur»—, y también se ocupa de los homófonos, tan abundantes en francés: podría decirse que esta vía léxica obvia - en la lectura silenciosa- la realización fonológica interna de la palabra ${ }^{6}$. La segunda vía que opera de modo general en la comprensión de la lectura es la vía fonológica, que reconoce los sonidos de las palabras antes de que

\footnotetext{
5 La noción aristotélica de error poético no es coincidente con la que aquí se utiliza, pues la primera se centra en los procesos de mimesis de la realidad que utiliza el arte; aun así, los dos errores se mostrarán parejos en el sentido de que ambos resultan convincentes, característica que Aristóteles considera esencial para atribuir al error carácter poético. Es más: el error deviene poético en la medida en que es capaz de potenciar algún tipo de emoción, emoción que, de no producirse el error, sería de naturaleza más tibia. En el caso que nos ocupa, comprender «se han matado» en lugar de «se han callado» entraría a formar parte de los errores que intensifican y dramatizan la recepción lectora. «El error propiamente poético [según Aristóteles] proviene de cierta impericia o impotencia en la manera como es imitado el objeto, que atañe a la contundencia o al poder persuasivo de la imitación, así como al carácter peculiar de la emoción despertada en el lector o en el espectador: la risa en la comedia, la compasión y el temor en la tragedia» (Trueba, 2000: 20).

${ }^{6}$ La elección de la lengua francesa y de un poema francés como campo de análisis para el presente artículo no se ha encontrado determinada únicamente por mi experiencia en torno a un caso particular de comprensión de un poema, sino al hecho mismo de que el francés es lengua marcadamente homofónica, y por ello apta para la observación del funcionamiento de la vía léxica de lectura.
} 
el cerebro encuentre su sentido, y opera sobre todo en el caso de las palabras desconocidas, a las que atribuye una pronunciación regularizada ${ }^{7}$. Incluso durante la lectura silenciosa intervienen las dos vías, extremo demostrado por el hecho de que la información fonológica activa áreas de nuestro cerebro como si se produjera realmente la pronunciación (Dehaene, 2007: 53). Si la realización fonológica es indispensable en la lectura silenciosa normal, aún lo es más en el caso de la poesía, y, singularmente en el caso de Verlaine; el simbolismo pretendía de modo general una naturaleza musical para el lenguaje poético, y, en el poema que nos ocupa, las cualidades de simultaneidad sonora que posee la música son transmitidas al lenguaje en forma de simultaneidad de significantes sostenidos por una misma cadena de sonidos: tal es el funcionamiento de los homófonos en general y del rébus (esa comprensión de una expresión diferente a la reconocible a partir de la ortografía y que está basada en la homofonía) ${ }^{8}$. Cargado de homofonías, el poema necesita, para ser comprendido a través de la lectura, que el reconocimiento grafemático acceda a la atribución directa de sentido por vía léxica. Es decir: la insistencia homofónica exige — complementariamente- que se refuerce la vía léxica de lectura. Y ello porque, por ejemplo, tras leer insistentemente en la segunda estrofa «elle me comprend», «elle seule, hélas», «elle seule», el oído lee el sentido de «elle et moi» («ella y yo») en la secuencia gráfica «et les moi/teurs de mon front blême». El rébus es contagioso, sobre todo porque ese «elle et moi» se inscribe en el contexto de confusión amorosa entre voz poética y mujer que domina los dos primeros cuartetos del soneto. Así pues, a menudo en la comprensión de un poema, y en particular en este verlainiano, las dos vías de lectura entran en disputa a la hora de la atribución del sentido, y ello propicia que se refuercen ambas vías de forma paralela: la lectura poética es ese refuerzo que atiende a vías divergentes en su sentido y que mantiene su coexistencia. La indecisión sobre qué vía seduce a la otra es en sí fuente de significancia poética.

\footnotetext{
7 «La voie directe, qui passe des lettres aux mots et à leur sens, permet de lire la plupart des mots suffisamment fréquents, mais achoppe sur les mots nouveaux, qui ne font pas partie du lexique mental. Inversement, la voie indirecte, qui passe d'abord des lettres aux sons, et, de là, à leur sens, joue un rôle crucial dans l'apprentissage des mots nouveaux, mais elle est inefficace pour les mots irréguliers comme «femme » et les homonymes comme «sot». Lorsque nous lisons à haute voix, les deux routes conspirent et collaborent l'une avec l'autre» (Dehaene, 2007: 70, 160-162).

${ }^{8}$ La convencional traducción de «rébus» por «jeroglífico» es imprecisa e incluso poco adecuada en este contexto, por lo que conservo el término en francés a lo largo de este artículo. Se trata, en todo caso, de un tipo de rébus que no contiene dibujos o representaciones icónicas, sino que se compone solo de grafemas. El ejemplo más clásico de rébus en francés es el siguiente: nez rond, nez pointu, main = Néron n'est point humain.
} 
El constante acecho de la vía fonológica sobre la léxica es clave para la comprensión poética en este poema, y por ello ha de serlo también a la hora de explicar el error de lectura de sus últimas palabras, un error que — puesto que ha sido calificado en estas páginas de «poético»— ha de incorporarse al sistema general de tensión léxica-fonológica del poema. Para verificar este aspecto es preciso detenerse en las diferentes zonas de reconocimiento por las que pasa una palabra (el reconocimiento visual se hace en 50 milisegundos, pero ello no quiere decir que todos los procesos mentales de la lectura terminen en ese tiempo), y analizar en qué medida ha podido producirse error en cada una de esas zonas.

En la región occipito-temporal de nuestro cerebro existe un área visual especializada en el reconocimiento de las letras. No parece que la atribución errónea de sentido a «se sont tues» tenga su origen en un mal reconocimiento de su cadena grafemática. Conviene sin embargo saber que, para ser leídas, las palabras necesitan ser fijadas por la mirada; el ojo esquiva lo que le es consabido, pues necesita avanzar. Avanza a saltos cada dos o tres décimas de segundo, y en cada salto no pude identificar más de diez o doce letras - tres a la izquierda del centro de la mirada y 7 u 8 a la derecha- (Dehaene, 2007: 40): el final de una palabra —o el de un verso- no caen en el centro de una mirada, evidentemente. ¿Cabe la posibilidad de que entre los participios «se sont tues» [ty] y «se sont tuées» [tue] el ojo no haya percibido una «é» de más? Esto es muy difícil, pues la presencia de una «é» (acentuada) tiene más entidad visual que la de una «e» sin acento; el lector francés sabe, además, que una «é» suena en francés, mientras que una «e» puede no ser pronunciada en absoluto; $y$, por si fuera poco, aunque los verbos auxiliares sean obviados por el ojo en sus saltos, los lexemas de los participios han de ser fijados por la mirada.

\section{HIPÓTESIS DEL OJO. MORFEMAS Y BIGRAMAS}

En este mismo nivel de reconocimiento visual de las letras, el ojo produce instantáneamente ciertas hipótesis para avanzar en la lectura y prestar más o menos atención a los diversos grafemas. Tales hipótesis se hacen previamente a todo acceso al sentido de la palabra, y pueden resultar equivocadas. Cada palabra es un árbol para el ojo, compuesto de letras, bigramas, sílabas y morfemas. Estos niveles de análisis se hacen, como se aprecia, sobre diferentes criterios (Dehaene, 2007: 51), criterios que no se explicitan en un nivel consciente: la distinción de morfemas no reposa sobre aval ninguno de sentido o de reflexión. El ojo encontrará, por ejemplo, el 
mismo lexema en «coro» $\mathrm{y}$ «decoro», cuando es evidente que no lo hay. Lo que tal vez ocurre en el final del poema de Verlaine es que el ojo acierta en parte y en parte se equivoca: «tues» («callado») incluye una raíz verbal + una forma participial con concordancia de femenino plural; y «tuées» («matado») incluye exactamente lo mismo (en francés las formas participales concuerdan con el sujeto cuando el auxiliar es el verbo «être»). Así que el ojo puede hacer una especie de abstracción que decide separar en ambas palabras las letras «t» $\mathrm{y}$ «u» de los morfemas finales. Evidentemente, el texto solo tiene la forma «tues» (callado), pero la forma «tuées» pudiera transparentarse erróneamente por razón de esta apuesta morfológica y su abstracción. Cabría pues pensar que el ojo distingue (acertadamente o no) componentes morfológicos, o — dicho en términos más exactos- que las zonas relativas a la percepción visual en el cerebro emiten una hipótesis de comprensión morfológica más rápidamente de lo que las zonas relativas al lenguaje registran la comprensión de sentido.

Afirma Dehaene que para reconocer una palabra es necesario que múltiples sistemas cerebrales se pongan de acuerdo en una interpretación unívoca de la entrada visual. El desacuerdo en la interpretación no es algo excepcional, y de hecho palabras cuya grafía se parece mucho entran en competición (2007: 80-81). En el caso de la confusión entre «se sont tues» y «se sont tuées», la segunda añade un grafema «é» — característica forma participial de los infinitivos regulares en «-er»- cuya presencia no parece que pueda pasar desapercibida. Pero la semejanza entre ambas formas participiales es mucho más plausible si se contempla desde la óptica de los bigramas, esas unidades de reconocimiento visual cuya existencia es puramente teórica, pues no han podido ser observadas las neuronas que las reconocerían ${ }^{9}$. Tales unidades se encuentran compuestas por bases de dos letras (Dehaene, 2007: 209), y cada palabra está codificada en varios bigramas. Puede pues ocurrir que palabras distintas (con letras intercambiadas o con ausencia de

9 Los bigramas podrían guardar cierto parentesco con los dífonos de que habla Saussure en su hipótesis de los anagramas (Starobinski, 1985). El dífono es una agrupación de dos fonemas en contacto, y los anagramas recogen la presencia de ciertos dífonos diseminados en un texto para formar un nombre o palabra-tema, de modo que su lectura rompe la linealidad y la consecutividad de los signos lingüísticos que forman dicho texto. Sumada a la perspectiva anagramática, la homofonía quizá pudiera estar designando la zona textual en la que leer una palabra-tema rectora en este poema de Verlaine; sería esta legible no en la extensión global del texto, sino en los diversos estratos de unos pocos dífonos densificados semánticamente por la homofonía, dífonos que se encontrarían presentes en la serie de bigramas comunes que codifican «tues» y tuées». Para aclarar este punto conviene llegar antes al final del recorrido de la lectura neurocognitiva que propongo, y por ello remito a la nota 11 y 12 del presente artículo. 
algunas de ellas) posean un código de bigramas muy parecido. Entre esas palabras se da una similitud abstracta, que facilita el error de lectura consistente en sustituir a la una por la otra. Los bigramas de la palabra «tues» son seis: tu, te, ts, ue, us, es. Los bigramas de «tuées» son diez: tu, té, te, ts, ué, ue, us, ée, és, es. De lo que se deduce que las dos palabras tienen un $60 \%$ de bigramas comunes, y ello permite concebir cierta posibilidad de confusión en el reconocimiento visual y, sobre todo, la posibilidad de amorçage.

\section{AMORÇAGE Y RÉBUS}

El amorçage —que significa «cebo» o «atracción»— es fenómeno que se produce tanto en el nivel ortográfico como en el fonológico (Dehaene, 2007: 56). Consiste en que la presentación de una primera cadena de letras o sonidos facilita la lectura de otra segunda, pues comparten un mismo morfema (aunque no tengan entre ellas una relación de sentido, y aunque dicho morfema común no sea más que una apuesta errónea de nuestro sistema de reconocimiento visual) (Dehaene, 2007: 49). Así, por ejemplo, «coro» puede amorcer «decoro». Atendiendo a esta circunstancia, cabe considerar la posibilidad de un amorçage instituido sobre un erróneo morfema «tu» común a «se sont tues» $\mathrm{y}$ «se sont tuées». Aunque la pronunciación de «se sont tues» esté determinada por la rima con «statues» [staty] — que se encuentra dos versos más arriba- y por tanto no haya ninguna posibilidad de leerlo equivocadamente como «se sont tuées», el amorçage viene avalado por el hecho de que «tues» es también la forma de la segunda persona del singular del indicativo del verbo «tuer» (matar), lo que refuerza la apuesta del ojo por un lexema común entre el participio «tues» (calladas) y el verbo «tuer». Hay que señalar, sin embargo, que no se trata de un verdadero amorçage, pues el verbo «tuer» no se encuentra en el poema, por mucho que la idea de la muerte le ronde $^{10}$. O quizá sí, pero precisa y exactamente en el mismo lugar que el verbo «taire». Lo cual nos desplaza desde la noción de amorçage hasta las de

10 Precisamente la idea de muerte presente a lo largo del poema pudiera justificar el error de comprensión de «tues» como un fenómeno propiciado por la memoria priming. La memoria priming —uno de los 6 tipos de memoria que existen hoy para la neurociencia (Rubia, 2006: 29)_ identifica algo como resultado de un contacto previo con ese algo, que en este caso pudiera ser no una palabra (pues el verbo «tuer» no está en el texto) sino el contenido de muerte que vehiculan diversos términos y segmentos significativos de los versos. Entendida de este modo amplio - y no solo como presentación subliminal frente al ojo de morfemas o imágenes que más tarde surgirán en la conciencia— la memoria priming podría ser considerada un instrumento de amorçage muy rentable para la lectura poética. 
homofonía y rébus, nociones estas cuya frecuencia e implicación en el sentido del poema han sido ya demostradas con anterioridad.

Aunque, como hemos dicho, la lectura aplica la vía léxica a los homófonos, cortocircuitando la vía fónica, la poesía, y en particular la de Verlaine, registra con especial énfasis la competencia entre ambas, competencia que es integrada dentro del sentido poético múltiple desplegado por el poema. Es importante señalar que, a partir de este momento, la homofonía analizada concierne no solo a la palabra «tues» sino a toda la expresión verbal que la contiene. Y así, «se sont tues» se convierte en un rébus de múltiples significados: en primer lugar, es posible oír «ce son tue» [sə sõ ty] («este sonido mata»), donde «tue» es verdadera forma verbal de tercera persona cuyo sujeto es «ce son» («este sonido»). Así el sentido de «tuer» («matar») se superpone homofónicamente en el participio de «taire». Evidenciado el rébus, mi convicción es que mis alumnos se basan sobre esta verdadera homofonía cuando comprenden el verbo «matar» en vez de «callar», y que, en realidad, no pronuncian en ningún momento durante su lectura silenciosa el participio del verbo «tuer» «se sont tuées».

Cabe preguntarse si esta comprensión del rébus («este sonido mata») tiene sentido en el contexto del poema. ¿A quién o qué mata ese sonido? Los dos tercetos señalan que la mujer se encuentra más allá de la muerte, pues su voz tiene la inflexión de los que se han callado definitivamente. Es el sonido de su voz el que mata: pero es «este sonido callado» de su voz —el nuevo homófono «ce son tu» [sə sõ ty] — el que mata. Así se constituye el segundo sentido del rébus, en el que el participio vuelve a reencontrar el sentido del verbo «taire»: «ce son tu».

El sonido callado de su voz tiene poderes de muerte, poderes de seducción para atraer a alguien hasta la muerte, esa zona en la que la mujer habita. ¿A quién atrae? El primer terceto recuerda del nombre de la mujer solo su carácter «suave y sonoro». «Sonoro»: es decir, recuerda su sonido. Un sonido recordado y a la vez olvidado — pues no se recuerda el nombre que compone-, un sonido callado y a la vez presente: «ce son: $t u »$ [sə sõ ty], «este sonido: tú» que recoge un tercer sentido del rébus; «ese sonido: tú» es el sonido del nombre con el que la mujer se habría nombrado a sí misma. A sí misma y al poeta. Mi nombre es «tú», le habría dicho, y en la confusión del nombre de ambos se habría expresado metonímicamente la confusión 
amorosa, o habría germinado este sueño frecuente y familiar en el que el poeta segrega de sí mismo una amante que es su doble ${ }^{11}$.

Sobrevenido el olvido del nombre, callado el tú (pronombre), «tu le tu», la confusión amorosa desaparece, y el sueño también: el sonido callado mata, «ce son tu tue». Mata al sueño, mata al amor engendrado en el sueño, los retira consigo más allá de la muerte, los hace desaparecer.

Los diversos sentidos del rébus pueden así componerse en una serie progresiva: la voz amada, como las voces que se ha callado («qui se sont tues») tiene un sonido que mata («ce son tue») pues es un sonido callado («ce son tu») en el que ya no se oye el sonido tú («ce son: $t u »)$. Dicho en breve: «ce son $t u$ tu tue» («ese sonido tú callado mata») ${ }^{12}$.

\section{RÉBUS, METÁFORA Y CEREBRO}

La lectura poética deja sus marcas en los procesos neurocognitivos de la lectura. En el caso del rébus, la lectura poética — contrariamente a la lectura normalizada - desactiva la automatización de la atribución de sentido que instituye la vía léxica para los homófonos, y subraya la indefinición de sentido a la que conduce la vía fónica. Es pues posible aventurar que los sentidos del rébus no se codificarían en la región temporal media, área cuyo «papel es recuperar en el seno de un léxico semántico los sentidos asociados a cada palabra» (Dehaene, 2007: 155), sino que, al ser un caso de selección de sentido entre varios posibles, la atribución de sentido se produciría en la región frontal inferior. Pero la cuestión del sentido semántico está lejos de ser conocida en términos neuronales: hoy en día se considera que las regiones frontales y temporales izquierdas quizá funcionan como «zonas de convergencia» de información procedente de zonas del córtex muy distantes entre sí. A ello se añade el problema de la alternancia de significados que el cerebro ha de codificar en el rébus. La alternancia, o, como hemos visto, la simultaneidad que les proporciona su aparición en contexto poético. Y es

11 Desde la perspectiva de la lectura, es posible señalar en «tues» bigramas que, aunque no se pronuncian, son interpretados por el ojo como fonemas potenciales. Interesa, en concreto, el bigrama «es», cuya pronunciación sería [ع /e] (en función de los acentos regionales) en una eventual secuencia gráfica «tu es» («tú eres»). Su pronunciación sería en ese caso homófona del participio «tuées»; cabe por ello decir que la lectura bigramática hace surgir del interior de la secuencia «se sont tues» la afirmación de la identificación («tu es», «tú eres») junto con la certeza de su muerte y desaparición («tuées»).

12 El bigrama «tu» remitiría pues, en un contexto anagramático, a un dífono [ty] en el que se leería de manera superpuesta la secuencia-tema que organiza todo el poema: «tu tu tue». 
que los procesos neurocognitivos operativos en la lectura - el lector de poesía lo sabe instintivamente- se ven complejamente inestabilizados y cuestionados por el funcionamiento poético.

Como afirma Dehaene, en la forma común de la lectura, «en rattachant la forme d'un mot à ses traits sémantiques, les connexions du lobe temporal résolvent le problème des fondements du sens» (2007: 158). El signo lingüístico es arbitrario, sí, pero solo en origen: «Lorsque nous apprenons une langue, cet arbitraire cesse d'exister à nos yeux. [...] Chacun des mots écrits s'attache solidement, par le biais de nos connexions cérébrales, aux neurones dispersés qui lui confèrent son sens» (Dehaene, 2007: 158). En cierta manera, el signo arbitrario, al devenir lenguaje simbólico fijado, encuentra una representación neurobiológica y neuroquímica en las conexiones del lóbulo temporal.

Pero el verdadero casse-tête del cerebro no es el signo ni el símbolo fijado, sino la metáfora, y el funcionamiento poético en general. El cerebro ha de deshacer las conexiones establecidas para el término de lenguaje que expresa la metáfora. O contemplar un tipo de conexiones alternativas. Dehaene sostiene que el cerebro reúne, cuando lee una palabra, una miríada de componentes de sentido - colores, movimientos, interpretación de intenciones, etc. - asociados a territorios distintos (2007: 156-158). Y esos componentes de sentido están recogidos por «zonas de convergencia» ${ }^{13}$. Pudiera suponerse que, en la lectura y comprensión de una metáfora, se efectúa una selección no habitual de los componentes de sentido, de modo que la zona de convergencia resulta otra, o simplemente que la zona de atribución es otra, o es doble (puesto que en la metáfora no desaparece el sentido de su referente completamente). Este desplazamiento de atribución

13 Existen, según la neurobiología, haces de conexiones que forman la sustancia blanca subyacente al córtex frontal y que enlazan territorios neuronales a larga distancia. La especie humana dispone de un sistema evolucionado de conexiones transversales que aumenta la comunicación entre ellas y rompe la modularidad cerebral permitiendo la recombinación flexible de los circuitos más específicos: juntando, combinando, sintetizando, evitando fraccionar los conocimientos. Los estudios de Edelman y Tononi (2000: 129-151, 169-185) adjudican un papel central en la integración de mapas neuronales a la actividad neuronal llamada reentrada, central en su Teoría de la Selección de los Grupos Neuronales (TNGS) y pilar en la creación de la conciencia. La conciencia de una escena perceptiva coherente (en la que las nociones de color, movimiento y forma proceden de diversos mapas cerebrales especializados de nuestro cerebro) no es fruto de un mapa coordinador superior que pone en red a los demás mapas neuronales implicados, sino de un proceso de reentrada entre los propios mapas cerebrales que crea sincronización entre sus actividades y las liga al sistema mnemónico categorial y axiológico creando un nudo dinámico: «l'aptitude à construire une scène consciente est l'aptitude à construire, en quelques fractions de seconde, un souvenir du présent» (Edelman, Tononi, 2000: 132). 
de sentido - con sus consecuencias en el orden cognitivo y neuronal- es lo que llamamos funcionamiento poético.

La desviación de la metáfora puede ser reabsorbida como normalidad por los circuitos de cableado neuronal gracias a la plasticidad (capacidad de automodelación a través del aprendizaje) de que está dotado el cerebro. La metáfora puede así, mediante su repetición, reinsertarse en un sistema de signos y en una cartografía cerebral creada expresamente para ella y por ella. Así se agotan sus capacidades de sorpresa, así se desactiva la capacidad poética de una metáfora. El cerebro la domestica en lenguaje consabido, y al hacerlo, marca en sus propias redes neuronales huellas que se activarán con más facilidad en el futuro. Pero el cerebro - que tiene como actividad esencial la producción de hipótesis para comprender el mundo- es adicto a los desafíos. Y para explorarse y sorprenderse a sí mismo es precisamente para lo que el cerebro humano sigue creando poesía.

\section{REFERENCIAS BIBLIOGRÁFICAS}

BAUDRILLARD, J. (1980). De la séduction. Paris: Galilée.

DEHAENE, S. (2007). Les neurones de la lecture. Paris: Odile Jacob.

EDELMAN, G. M \& TONONI, G. (2000). Comment la matière devient conscience. Paris: Odile Jacob.

RUBIA, F. (2006). ¿Qué sabes de tu cerebro? Madrid: Temas de Hoy.

STAROBINSKI, J. (1985). Les mots sous les mots: les anagrammes de Ferdinand de Saussure. Paris: Gallimard.

TRUEBA ATIENZA, C. (2000). «El error poético en Aristóteles». Theoria: Revista del Colegio de Filosofía (México: Universidad Nacional Autónoma de México)10, 11-21.

VALÉRY, P. [1991 (1972)]. El señor Teste. México: Universidad Nacional Autónoma de México. [(1969). Monsieur Teste. Paris: Gallimard.]

VERLAINE, P. (1958). Poèmes Saturniens. Paris: Armand Colin.

Recibido el 30 de abril de 2013.

Aceptado el 19 de septiembre de 2013. 
